\title{
Staging lung cancer: Current controversies and strategies
}

\author{
Riyad Karmy-Jones MD, Robert H Hyland MD, Joseph W Lewis Jr MD, Paul Kvale MD \\ Division of Thoracic Surgery, University of Washington, Seattle, Washington; Divisions of \\ Thoracic Surgery and Pulmonary Medicine, Henry Ford Hospital, Detroit, Michigan; \\ Department of Medicine, Wellesley Central Hospital, Toronto, Ontario
}

R Karmy-Jones, RH Hyland, JW Lewis Jr, P Kvale. Staging lung cancer: Current controversies and strategies. Can Respir J 1997;4(6):297-305.

A consistent approach to staging is required for the rational management of lung cancer. This paper was prepared at the request of the Standards Committee of the Canadian Thoracic Society, and reviews and discusses the relative merits of the available methods of staging. Whichever methods are chosen by a particular institution, the following points must be stressed. No patient can be considered automatically 'unresectable' when chest radiography and/ or computed tomography demonstrate adenopathy or only suggest local invasion. Clinical and/or radiographical evidence suggesting extensive local or metastatic disease should be evaluated as completely as possible before subjecting the patient to a possible 'nontherapeutic' thoracotomy. Finally, in some cases thoracotomy is required to decide whether the lesion is 'completely' resectable.

Key Words: Lung cancer, Staging

\section{Stadification du cancer du poumon : contro- verses et approches actuelles}

RÉSUMÉ : La stadification nécessite une approche cohérente pour traiter le cancer du poumon de façon rationnelle. Le présent article a été préparé à la demande du Comité des normes de la Société canadienne de thoracologie. Il passe en revue et discute des avantages relatifs des différentes méthodes de stadification qui sont disponibles. Quelles que soient les méthodes choisies par un établissement particulier, on doit insister sur les points suivants : on ne peut automatiquement classer un patient comme non candidat à une résection quand la radiographie pulmonaire ou la tomodensitométrie mettent en évidence une adénopathie ou laissent croire à une invasion locale. Les preuves radiographiques et/ou cliniques qui font croire à une maladie locale étendue ou métastatique devraient être évaluées en profondeur avant de faire subir au patient une éventuelle thoracotomie non thérapeutique. Finalement, dans certains cas, il est nécessaire de procéder à une thoracotomie pour savoir si la lésion est entièrement résécable.
$\mathrm{S}$ taging has been called the key to the rational management of lung cancer (1-2). Recognizing that complete resection is the best treatment for nonsmall cell lung cancer (NSCLC), staging is performed with the following goals in mind: identify patients most likely to benefit from complete resection; keep the incidence of 'nontherapeutic' thoracotomies as low as possible, ideally $9 \%$; ensure that no patient be denied the chance of a curative resection on the basis of indeterminate radiographical or clinical findings alone; identify candidates for neoadjuvant protocols; and obtain prognostic information (2-6). The aim of this paper is to review and compare the available methods of staging when presented with a patient with a known diagnosis of lung cancer, and to discuss their relative merits in different clinical settings.

\section{STAGING SYSTEMS}

The initial tumour-node-metastases (TNM) system for staging cancer was described in 1946 by Denoix (7). The American Joint Committee for Cancer Staging and End Results Reporting (AJCC) applied the TNM descriptors to lung 
TABLE 1

Tumour-node-metastases classification for staging lung cancer

\section{T: Primary tumour}

TX Tumour proven by the presence of malignant cells in bronchopulmonary secretions but not visualized radiographically or bronchoscopically, or any tumour that cannot be assessed, as in a retreatment staging

T0 No evidence of primary tumour

TIS Carcinoma in situ

T1 Tumour is $3.0 \mathrm{~cm}$ or less in greatest dimension, surrounded by lung or visceral pleura and without evidence of invasion proximal to a lobar bronchus at bronchoscopy

T2 Tumour is more than $3.0 \mathrm{~cm}$ in greatest dimension or of a size that either invades the visceral pleura or has associated atelectasis, or obstructive pneumonitis extending to the hilar region. At bronchoscopy, the proximal extent of demonstrable tumour must be within a lobar bronchus or at least $2.0 \mathrm{~cm}$ distal to the carina. Any associated atelectasis or obstructive pneumonitis must involve less than an entire lung

T3 Tumour of any size with direct extension into the chest wall (including superior sulcus tumours), diaphragm, or the mediastinal pleura or pericardium without involving the heart, great vessels, trachea, esophagus or vertebral body, or a tumour in the main bronchus within $2 \mathrm{~cm}$ of the carina without involving the carina

T4 Tumour of any size with invasion of the mediastinum or involving heart, great vessels, trachea, esophagus or vertebral body or carina, or presence of malignant pleural effusion

\section{$\mathrm{N}$ : Nodal involvement}

No No demonstrable metastasis to regional lymph nodes

N1 Metastasis to lymph nodes in the peribronchial or ipsilateral hilar region, or both, including direct extension

N2 Metastasis to ipsilateral mediastinal and subcarinal lymph nodes

N3 Metastasis to contralateral mediastinal, contralateral hilar, ipsilateral or contralateral scalene, or supraclavicular lymph nodes

\section{M: Distant metastasis}

M0 No (known) distant metastasis

M1 Distant metastasis present

cancer (8). Subsequently, it became apparent that, within the same clinical stage, there were subsets with significantly different prognoses. In 1986, Mountain (9) presented the currently used staging system, a combined effort by the AJCC and the International Union Against Cancer (Tables 1,2). An explanation of the classifications within this paper are outlined in Tables 1 and 2. Within stage III there are further clinically distinct subgroups, each with different prognoses and treatment responses (Table 3) (10). Therefore, the current TNM system will probably undergo further modification.
TABLE 2

Tumour-node-metastases grouping into stages

\begin{tabular}{lccc}
\hline Stage & $\begin{array}{c}\text { Tumour } \\
\text { subgroup }\end{array}$ & $\begin{array}{c}\text { Nodal } \\
\text { subgroup }\end{array}$ & $\begin{array}{c}\text { Metastases } \\
\text { subgroup }\end{array}$ \\
\hline Occult carcinoma & TX & N0 & M0 \\
Stage 0 & TIS & N0 & M0 \\
Stage I & T1 & N0 & M0 \\
Stage II & T2 & N0 & M0 \\
Stage IIIa & T1 & N1 & M0 \\
& T2 & N1 & M0 \\
Stage IIIb & T3 & N0 & M0 \\
& T3 & N1 & M0 \\
Stage IV & T1 to T3 & N1 to N3 & M0 \\
\hline
\end{tabular}

See Table 1 for explanation of subgroups

The staging process can be broken down into a clinical stage (cTNM) and a pathological stage (pTNM). cTNM, determined by clinical, radiographical and invasive studies, is used to plan the optimal therapeutic approach. pTNM, determined after surgery, suggests the prognosis and the role of adjuvant regimens (Table 4) (11,12). Analysis of the resected specimen by using cell biological techniques may be added to the assesment of pTNM and affect postoperative treatment planning (10).

The TNM system is applicable to both NSCLC and small cell lung cancer (SCLC). SCLC, however, is usually described as 'limited' or 'extensive' based on whether it can be encompassed by one radiation port (13).

As important as these methodologies are, it is equally important to determine whether the patient has sufficient cardiopulmonary reserves to undergo a resection.

\section{METHODS OF STAGING}

A number of staging methods can assess each of the tumour (T), node (N) and metastases (M) descriptors (Table $5)$. These will be discussed in turn.

\section{Assessing T status}

Clinical examination: Examination may suggest advanced local disease (Table 6). Pulmonary symptoms are not specific enough to rule out curative resection by themselves $(14,15)$. However, extrapulmonary intrathoracic symptoms imply advanced local disease that may well preclude curative resection and require further investigation before proceeding to thoracotomy.

Chest radiograph: While not exact in determining the true extent of endobronchial disease, the chest radiograph (CXR) can provide evidence of intrathoracic spread or invasion, such as diaphragmatic elevation (implying possible phrenic nerve involvement), vertebral or rib lesions, pleural or pericardial effusion, and synchronous (more than one primary growth) or metastatic lesions.

Computed tomography: Computed tomography (CT) pro- 
TABLE 3

Clinically distinct subgroups within stage III nonsmall cell carcinoma lung cancer

\begin{tabular}{lll}
\hline Stage & Tumour and nodal subgroups & Description \\
\hline IIIA & T1-3 N0-1 & $\begin{array}{l}\text { Peripheral lesion with chest wall invasion or less than } 2 \mathrm{~cm} \text { from the carina. Some } \\
\text { superior sulcus tumours (resectable) }\end{array}$ \\
Prognosis and therapy defined by N2 status (staging of N2 nodes determines whether \\
surgery can be primary treatment or whether surgery can be contemplated as part of \\
neoadjuvant regimens) \\
LIIB
\end{tabular}

Adapted with permission from reference 10

TABLE 4

Prognosis of 1737 patients after resection of lung cancer according to the postoperative tumour-node-metastases (TNM) classification

\begin{tabular}{llcc}
\hline Stage & TNM & $\begin{array}{c}\text { Number of } \\
\text { patients }\end{array}$ & $\begin{array}{c}\text { Five-year } \\
\text { survival rate (\%) }\end{array}$ \\
\hline I & T1 N0 M0 & 245 & 75.5 \\
& T2 N0 M0 & 291 & 57.0 \\
II & T1 N1 M0 & 66 & 52.5 \\
& T2 N1 M0 & 153 & 38.4 \\
IIIA & T3 N0 M0 & 106 & 33.3 \\
& T3 N1 M0 & 85 & 39.0 \\
\multirow{2}{*}{ IIIB } & T1-T3 N2 M0 & 368 & 15.1 \\
& T1-T3 N3 M0 & 55 & 0 \\
IV & T4 any N M0 & 104 & 8.2 \\
& Any T any N M1 & 258 & 7.5 \\
\hline
\end{tabular}

Adapted with permission from reference 11

vides a relatively accurate determination of $\mathrm{T}$ status. A lesion that seems large on CXR may be found to be much smaller on $\mathrm{CT}$, the size discrepancy due to postobstructive pneumonitis or volume loss. CT may also suggest obvious vertebral or mediastinal invasion. However, if there are only indeterminate findings of local invasion (abutment or loss of fat plane between the malignancy and adjoining mediastinal structures), resection is possible in up to $82 \%$ of cases (16). More specifically, it is important to evaluate the following features: less than $3 \mathrm{~cm}$ of contact in one cut between the tumour and mediastinal structure in question; less than 90 degrees of contact with the aorta (ie, one-quarter of the circumference); and/or the presence of an intact mediastinal fat plane. If any one of these is present, resection is possible in up to $97 \%$ of cases (16). In terms of chest wall involvement, CT has an accuracy of $39 \%$, specificity of $40 \%$ and sensitivity of $39 \%$ when considering features such as pleural thickening, obtuse angle between mass and adjacent pleural surface, and/or thickening of pleural fat (17). Prethoracotomy thoracoscopy appears to be a useful adjunct in such settings (2).

Magnetic resonance imaging: While not recommended as a

\begin{tabular}{l} 
TABLE 5 \\
Methods of staging \\
\hline Noninvasive \\
Clinical examination \\
Chest x-ray \\
Nuclear studies \\
Magnetic resonance imaging \\
Computer assisted tomography scan \\
Positron emission tomography scan \\
Invasive \\
Bronchoscopy \\
Needle aspiration \\
Cervical mediastinoscopy \\
Extended cervical mediastinoscopy \\
Mediastinotomy \\
Thoracoscopy \\
Thoracotomy
\end{tabular}

routine study, magnetic resonance imaging (MRI) is more accurate than CT in determining the degree of vertebral, spinal canal or (arguably) chest wall invasion, and may be the modality of choice for evaluating superior sulcus tumours (14). MRI defines relationships to vessels but tends to overestimate mediastinal invasion (18).

Bronchoscopy: Bronchoscopy is important in determining the endobronchial $\mathrm{T}$ stage and should be done by the surgeon just before thoracotomy at the same anesthetic sitting, even if already performed by a pulmonologist, because it may have direct impact on the proposed plan for resection (1). Some patients with $\mathrm{T} 3$ or even $\mathrm{T} 4$ lesions may be candidates for a sleeve resection, and bronchoscopic biopsies are needed to ensure that there is no subepithelial spread beyond the limits of resection (19-21). On occasion, bronchoscopy reveals that a tumour seemingly involving the carina or right mainstem bronchus actually originates in the right upper lobe and prolapses into, but does not directly invade, the more proximal airway. Finally, synchronous (second primary) lesions may rarely be identified by endoscopy.

Thoracoscopy: Thoracoscopy allows direct prethoracotomy 
TABLE 6

Clinical symptoms of lung cancer

Pulmonary symptoms

Dyspnea

Cough

Hemoptysis

Wheeze

Pneumonitis (atelectasis and/or pneumonia and/or abscess)

Extrapulmonary intrathoracic symptoms

Dyspnea (phrenic nerve involvement and/or pleural or pericardial effusion, pneumothorax)

Chest pain (pneumonitis and/or chest wall invasion and/or nerve involvement)

Superior vena cava syndrome

Pancoast syndrome

Dysphagia (esophageal obstruction)

Back pain (vertebral invasion and/or metastasis)

Hoarseness (recurrent nerve involvement by direct invasion from left upper lobe or N2 nodal involvement)

Horner's syndrome

Extrathoracic nonmetastatic symptoms

Nonspecific symptoms (anorexia and/or fatigue and/or weight loss)

Metabolic symptoms (Cushing's syndrome and/or syndrome of inappropriate antidiuretic hormone secretion and/or hypercalcemia and/or ectopic gonadotrophic)

Neuromuscular symptoms (carcinomatous myopathy and/or peripheral neuropathies and/or subacute cerebellar degeneration and/or encephalomyelopathy)

Skeletal symptoms (clubbing and/or pulmonary hypertrophic osteoarthropathy)

Vascular symptoms (migratory thrombophlebitis and/or nonbacterial endocarditis and/or arterial thrombosis)

Hematological symptoms (anemia and/or fibrinolytic purpura and/or nonspecific leukocytosis and/or polycythemia)

Extrathoracic metastatic symptoms

Bone pain

Focal neurological defects

Headaches

Abdominal pain

Jaundice

Weight loss

assessment of pleural, chest wall and mediastinal invasion $(2,22)$. It is particularly important in the presence of pleural effusion because the resectability rate, even in the presence of cytologically negative fluid, is as low as $5.5 \%$ (23). Some groups advocate its routine use before all surgery (22).

\section{Assessing N status}

Clinical examination: Examination of the neck may identify adenopathy (N3) that would require biopsy confirmation. This is particularly important in the presence of superior sulcus tumours. Patients with left-sided lesions and hoarseness may have fixed N2 nodes involving the recurrent laryngeal nerve. If confirmed histologically, this is a contraindication to resection, as is extrapulmonary intrathoracic symptoms due to adenopathy.

CXR: Except when gross adenopathy is identified, CXR does not adequately assess lymph node spread. Gross medi-
TABLE 7

Indications for mediastinoscopy

Absolute indications

Enlarged mediastinal lymph nodes

Relative indications

T2 or T3 primary tumour

Lesion within medial third of lung field

Adenocarcinoma or large cell undifferentiated tumours identified on preoperative biopsy

Suspected multiple primary tumours or synchronous lesions

Presence of small cell cytology in suspected stage I lesions

Presence of vocal cord paralysis with left upper lobe primary tumour

Intent to use neoadjuvant therapy

astinal adenopathy noted on plain CXR is associated with an extremely poor prognosis, with three-year survival averaging $9 \%$ (24). Biopsy confirmation of metastatic involvement is required.

$\boldsymbol{C T}$ : CT is currently the most effective noninvasive method of assessing possible mediastinal lymph node metastases (14). CT evidence of adenopathy is usually nodes with a short axis diameter $(1.0 \mathrm{~cm})$. A meta-analysis of CT accuracy in defining mediastinal node involvement ascribed a sensitivity of $79 \%$, a specificity of $78 \%$ and an overall accuracy of $80 \%$ (25). Between $5 \%$ and $30 \%$ of 'abnormal' nodes are positive for cancer, while as many as $15 \%$ of patients with 'normal' nodes are positive $(2,4,26)$. The false negative rate increases in the presence of adenocarcinoma, large cell tumours and with all central T3 cancers $(27,28)$. Thus, surgical resectability cannot be excluded solely on the basis of CT evidence of adenopathy, and, by the same token, certain lesions are associated with increased risk of mediastinal nodal involvement despite a 'negative' CT.

Positron emission tomography: Positron emission tomography, in conjunction with F-18-fluorodeoxyglucose, has shown some promise in detecting superior mediastinal and supraclavicular involvement, although inflammatory lesions may cause false positive readings (29-32). These findings need to be confirmed histologically.

Mediastinoscopy and mediastinotomy: Mediastinoscopy is safe (percentage morbidity) and, when used routinely, reduces nontherapeutic thoracotomy rates to $5 \%(5,33)$. It identifies patients with false positive CT mediastinal adenopathy, as well as the subset that are found to have 'minimal' (intracapsular spread without fixation, solitary, lowest station) mediastinal nodal involvement (with $25 \%$ to $40 \%$ fiveyear survival following complete resection) (1,2,4,20). Finally, a proportion of these patients may be eligible for enrolment into neoadjuvant protocols, and many of these protocols require invasive staging $(1,2,4,10,11,20,34,35)$. However, it is not clear whether, in the absence of CT evidence of mediastinal adenopathy, mediastinoscopy increases survival advantage $(1,26,36,37)$. Thus, depending on what a particular centre considers to be the upper limit of normal, many centres advocate 'selective' mediastinoscopy (Table 7) (2). 
Mediastinoscopy cannot assess posterior subcarinal, aortopulmonary, para-aortic and/or subaortic, periesophageal and pulmonary ligament nodes. Biopsy of the aortopulmonary and para-aortic and/or subaortic (anterior mediastinal) nodes (stations 5 and 6) is indicated if there is evidence of enlarged aortopulmonary window nodes and cervical mediastinoscopy is negative. The primary concern is whether the nodes are fixed to the pulmonary artery because the five-year survival rate after complete resection in the presence of resectable subaortic disease only approaches that of survival after resection of $\mathrm{N} 1$ disease $(38,39)$. While traditionally performed by anterior mediastinotomy, extended cervical mediastinoscopy, which provides a single staging method for left upper lobe tumours, is performed, but only at a few centres (40).

Bronchoscopy: At the start of the procedure, suspected vocal cord paralysis can be evaluated. This may confirm CT evidence of extensive $\mathrm{N} 2$ nodal disease with involvement of the recurrent nerve. Carinal widening or other evidence of adenopathy can be detected, and these nodal areas biopsied, with a Wang needle with a sensitivity of $50 \%$ and specificity of 96\% $(41,42)$. Some centres obtain a CT before initial bronchoscopy so that accessible areas of adenopathy can be biopsied at that time and, thus, avoid mediastinoscopy in many instances. However, the use of this approach varies between institutions depending on the confidence and skill of both the bronchoscopist and pathologist. One of the authors of this report has used this technique to biopsy multiple nodal areas including both right tracheobronchial nodes. Preliminary results suggest that the yield is similar to mediastinoscopy. When lymph tissue is obtained from suspicious nodes and is negative for cancer, our current practice is to perform mediastinoscopy. If the area is 'missed', an alternative that is being evaluated is bronchoscopic Wang needle biopsy with real-time $\mathrm{CT}$ guidance.

Fine needle aspiration: Clinically palpable neck nodes can be aspirated or biopsied under local anesthesia (14). Areas of adenopathy, both within and beyond the 'range' of mediastinoscopy, have been successfully biopsied using CT-guided techniques with a reported sensitivity of $88 \%$ and specificity of $100 \%$ (43). The results are operator-dependant, and each institution must evaluate its own results before making firm conclusions regarding the use of this method in their own setting. Transesophageal ultrasound-guided needle biopsy has also been described for selected patients (44).

Scalene node biopsy: While palpable scalene nodes should be biopsied, routine biopsies have not been performed for the past 20 to 30 years. However, a recent report documented microscopic involvement of the scalene nodes in $15 \%$ of patients with positive $\mathrm{N} 2$ disease and $68 \%$ of patients with contralateral disease, and recommended routine mediastinoscopic scalene node biopsies in such patients (45).

Thoracoscopy: Thoracoscopy can be used to biopsy many of the nodal areas, but it is particularly useful for assessing the posterior subcarinal and aortopulmonary window nodes, and has been advocated as a routine prethoracotomy staging tool by some centres $(2,22)$. Mediastinoscopy still appears superior in its ability to assess the upper mediastinal nodes $(2,14)$.
Assessing M status

Clinical examination: While the presence of extrathoracic, nonmetastatic symptoms (Table 6) does not preclude curative resection, generalized debility and/or weight loss is often an indication of widespread disease (14). Approximately $1 \%$ of patients have evidence of cutaneous metastases that should be biopsied. Focal neurological, bony or abdominal symptoms should prompt head CT, bone scan or abdominal $\mathrm{CT}$, respectively. Elevated serum alkaline phosphatase (liver or bone fraction) or calcium should prompt a similar evaluation with imaging studies.

Radiographic studies: CXR and/or CT may demonstrate rib changes or other bony lesions consistent with metastases. Synchronous or intrapulmonary metastatic lesions may also be detected.

It is routine to include the upper abdomen in the CT evaluation of pulmonary malignancies. Approximately $7 \%$ of patients have evidence of adrenal or hepatic involvement (46). The risk of adrenal enlargement due to a metastasis increases if the adrenal is greater than $3 \mathrm{~cm}$ in diameter. Suspicious lesions must be confirmed by biopsy before denying an otherwise resectable patient an opportunity for curative surgery.

Many centres feel that it is not warranted to obtain routine bone scans or head CTs in patients with NSCLC that appear to be resectable without laboratory or clinical evidence of metastases $(47,48)$. Others feel that all nonsquamous NSCLC, as well as all stage III tumours, should have routine cerebral imaging because of the greater propensity for microscopic early spread (49).

A positive bone scan should be followed by appropriate correlative plain radiographs for confirmation. A negative radiograph in the presence of a positive bone scan does not exclude metastatic disease, and further investigation, including MRI, CT or biopsy, may be required.

\section{THE ROLE OF THORACOTOMY IN STAGING}

It is apparent from the above discussion that a proportion of patients may require thoracotomy to determine ultimately whether complete resection is possible. In addition, complete staging at thoracotomy determines both prognosis and the role of adjuvant treatments $(10,50)$. A more difficult and controversial area is how to determine at thoracotomy that resection will not benefit a patient, especially because there is an emotional pressure 'to do something'. Careful exploration may reveal invasion of mediastinal structures or the vertebrae that would, except in rare circumstances, preclude curative resection. Some centres perform mediastinal lymph node dissection before any resection because they feel that extensive spread precludes curative surgery.

\section{INTEGRATING STAGING INTO ATREATMENT PLAN FOR NSCLC}

Apparently operable NSCLC: It appears that T1 and T2 lesions with no evidence of mediastinal adenopathy on CT scan do not require more invasive staging. This does not appear to increase the incidence of 'nontherapeutic' thoracoto- 


\section{Preoperative Pulmonary Function Testing}

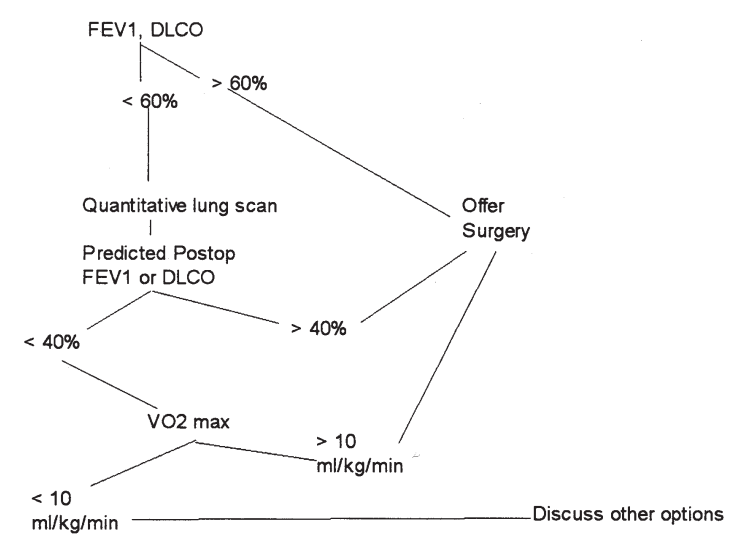

Figure 1) Scheme for the progressive preoperative evaluation of a patient being considered for pulmonary resection. DLCO Diffusion capacity for carbon monoxide; FEV $V_{1}$ Forced expiratory volume in 1 s; Postop Postoperative; $V_{2 \max }$ Maximum oxygen volume

mies or decrease the cure rate (34). Staging of T3 lesions without evidence of adenopathy is controversial. Survival is markedly reduced in T3N2 stage IIIA tumours, and if a particular centre plans induction regimens for these patients, biopsy of the upper mediastinal N2 nodes should be performed routinely (2). Other centres prefer to go straight to thoracotomy, with plans for complete mediastinal node dissection and adjuvant therapy, although there is no proven survival benefit $(11,20,50)$.

Apparently inoperable NSCLC: Curative resection should not be withheld on the basis of indeterminate radiographical findings alone. Central lesions that appear to invade the mediastinum but are otherwise operable may require thoracotomy for definition (16). Occasional survivors are reported from minimal resection of the vena cava, aorta, esophagus, atrium and vertebral body $(11,20)$. Prethoracotomy mediastinoscopy should be performed where this possibility is suggested by CT scan because central T3N2 and T4N2 lesions treated by resection alone are associated with essentially no chance of five-year survival.

Patients with adenopathy on CT should also undergo more invasive staging by one of the methods described previously. Ten per cent of patients with NSCLC and positive N2 disease have single, ipsilateral, intracapsular spread only and are still candidates for resection $(1,2,4,20)$. The remainder may be candidates for neoadjuvant therapy. Such regimens for stages IIIA and IIIB have been described, with a subsequent complete resection rate as high as $73 \%(11,20,35)$.

Although there have been occasional reports of survivors with NSCLC with stage IV disease following surgery, the role of resection has generally been limited to patients with isolated, resectable, cranial metastases $(11,20)$. Usually craniotomy precedes thoracotomy to ensure complete resectability, the absence of other occult metastases and full patient recovery. Resection in patients with isolated adrenal metastases has also been described with a 38\% three-year survival rate, but this approach is still investigational (51).

High risk patients: It is important to consider both 'resectability' (ie, the tumour) and 'operability' (ie, the patient's ability to tolerate surgery). A more aggressive approach to staging is justifiable in patients whose general medical condition (usually cardiopulmonary) puts them at high risk for thoracotomy. Individuals with primary cardiac limitations may require stress tests, echocardiography and possibly coronary angiography. Patients with correctable coronary disease may undergo preoperative angioplasty or bypass, or, rarely, simultaneous coronary bypass and lung resection (52). The major question is whether pulmonary reserves are adequate to tolerate the proposed resection $(53,54)$. Unfortunately, no single preoperative test is sufficiently accurate in predicting the risk of surgery, but rather an integrated approach, taking into account clinical judgement and a number of physiological variables, is often needed (Figure 1) (55). Initial tests include a complete physical examination, stair climbing, spirometry (values expressed as a percentage of predicted being more valuable than absolute numbers) and arterial blood gas determinations (56). Patients with limitations (usually forced expiratory volume in $1 \mathrm{~s}\left[\mathrm{FEV}_{1}\right]$ or diffusion capacity for carbon monoxide [DLCO] less than $60 \%$ predicted) should generally undergo quantitative (nuclear) split-perfusion testing. If it is predicted that postoperative $\mathrm{FEV}_{1}$ or DLCO will be less than $40 \%$, a maximum progressive incremental exercise is indicated. If maximum exercise capacity is less than $30 \%$ predicted or maximum oxygen consumption is less than $10 \mathrm{~mL} / \mathrm{kg} / \mathrm{min}$, the risk of resection is extremely high but does not absolutely preclude surgery (57).

Intraoperative studies may have a role in determining how well a resection can be tolerated. Initial data suggest that long term cardiac disability (but not mortality) may be predicted at the time of 'test clamping' of the pulmonary artery by recording a right ventricular ejection fraction (RVEF) of 35\%, a pulmonary vascular resistance (PVR) of at least 200 dyne $\cdot \mathrm{s} \cdot \mathrm{cm}^{-5}$ and/or a PVR:RVEF ratio of 5.0 (57). Some groups use a variety of 'angioplastic' and 'bronchoplastic' reconstructions to preserve as much functional lung as possible in patients who are identified as high risk $(19,21,58)$. Patients with peripheral $\mathrm{T} 1$ lesions without evidence of mediastinal metastases who are not suitable for thoracotomy may be considered for thoracoscopic wedge resection, although the risk of local recurrence is increased (59).

Patients whose pulmonary reserves fail to achieve institutional 'limits' should not be arbitrarily rejected for surgery, but rather all possible options should be discussed (54). Many patients improve with preoperative pulmonary therapy, bronchodilators and smoking cessation, and on retesting may become candidates for surgery. Improvements in postoperative care, especially pain management, have resulted in decreased morbidity in high risk patients following thoracotomy $(54,55)$. Each centre needs to evaluate its own outcomes to determine individual limits. 
Local recurrence and restaging following induction therapy: The approach to staging in the setting of local recurrence or following induction therapy is the same as with the initial workup, except that mediastinoscopy (redoing or following chemotherapy) is more hazardous, and most centres advocate cerebral CT and bone scans as mandated by symptoms and signs, if not 'routinely'. Ideally, suspicious mediastinal adenopathy should be biopsied before thoracotomy by one of the techniques described earlier because completion pneumonectomy is associated with increased operative risk (60).

\section{STAGING SCLC}

The role of surgery in SCLC is limited because chemotherapy is considered the primary treatment. Staging is mainly used for prognosis and to determine eligibility for treatment protocols (61). However, application of TNM staging reveals that stage I SCLC can be resected with $25 \%$ fiveyear survival or higher, assuming chemotherapy is also given. Frequently, stage I SCLC is diagnosed after resecting a solitary pulmonary nodule when this diagnosis was not anticipated preoperatively. Extensive staging is still required. Bone marrow biopsy (unilateral) is usually included, although its worth has been questioned (61). Chemotherapy is mandatory, either preoperatively or postoperatively, because patients with apparent stage I SCLC should still be regarded as having systemic disease. Patients with lesions that are found to be stage II at thoracotomy should receive postoperative adjuvant therapy. Some preliminary data suggest that patients with preoperative evidence of N1 or minimal N2 disease benefit from induction chemotherapy and adjuvant surgery $(62,63)$. It should be stressed that chemotherapy remains the primary treatment for SCLC, and surgery may be used as an alternative to radiotherapy for local control, in some cases under strict investigational protocols only. No randomized studies have compared adjuvant surgery with adjuvant chemotherapy and radiation.

Approach to diagnosis of adenocarcinoma: Diagnosis of adenocarcinoma, unlike other cell types that commonly arise in the lung, does not necessarily imply primary lung cancer, and on pathological examination alone it may be difficult to impossible to confirm a lung origin. One therefore needs to consider the possibility of metastatic disease, even when the lesion appears to be solitary. This applies to bronchioloalveolar carcinoma (BAC) as well, in that approximately $16 \%$ of adenocarcinomas metastatic to lung may simulate BAC in their growth pattern (64). It is also important to recognize that BAC has a unique propensity for multifocal growth with a reported incidence of $25 \%$ (65). Further, a prospective combined CXR/CT scan study showed that multicentricity in BAC was missed in $37 \%$ of cases (66).

\section{STAGING CARCINOID TUMOURS}

Carcinoid tumours have been considered a tumour type in a spectrum of Kulchitsky cell or neuroendocrine neoplasms, which range from typical carcinoid through atypical carcinoid and, finally, SCLC (67). Typical carcinoids have low malignant potential, with less than 5\% incidence of lymph
TABLE 8

Requirements for resection of metastatic pulmonary lesions

Primary site controlled

No better therapy

No extrathoracic spread

Patient can tolerate the proposed resection

All of the disease can be resected

node metastases and greater than $80 \%$ cure rates with surgery (68). Atypical carcinoids have an incidence of lymphatic metastases in up to $70 \%$, with a 10-year survival of less than $50 \%(68,69)$. Clinical evidence of carcinoid syndrome implies atypical features, a large lesion or metastases, with rare exceptions (70). The most recent authoritative classification of neuroendocrine neoplasms adds a tumour type called large cell neuroendocrine carcinoma (71). This is a high grade carcinoma that fits in the spectrum somewhere between atypical carcinoid and SCLC, with a prognosis approaching that of SCLC.

Surgery is still the primary mode of treatment, but accurate intraoperative staging may confirm lymphatic metastases, which may indicate a role for adjuvant therapy (69).

\section{STAGING METASTASES TO THE LUNG}

Resection can be considered for pulmonary metastases from extrathoracic malignancies under certain circumstances (Table 8). Some lesions (breast, thyroid, renal cell, melanoma and colon) may be associated with endobronchial metastases, necessitating bronchoscopy. If the primary lesion is associated with lymphatic metastases and there is evidence of mediastinal adenopathy, these potential N2 nodes should be biopsied (72).

\section{SUMMARY}

Staging lung cancer requires a physiological as well as pathological assessment. It is laborious, and many patients are unsuitable for resection. There are some 'grey' areas where definite recommendations cannot be made, and each centre needs to review its own results. Lymphadenopathy can be assessed by mediastinoscopy, bronchoscopy, CT-guided needle biopsy and/or thoracoscopy. There is evidence for 'selective' mediastinoscopy, but there is also strong support for 'routine' mediastinoscopy. Thoracoscopy can be viewed in the same fashion. The definition of what constitutes a 'physiological' high risk patient also varies between centres. Despite all of these issues, there are three basic 'guidelines'.

1. No patient can be considered automatically 'unresectable' when chest radiography and/or CT demonstrates adenopathy or only suggests local invasion.

2. Clinical and/or radiographical evidence suggesting extensive local or metastatic disease should be evaluated as completely as possible before subjecting the patient to a possible 'nontheraputic' thoracotomy.

3. In some cases, thoracotomy is required to determine 
definitively whether the lesion is 'completely' resectable.

\section{CONCLUSIONS}

Because resection of lung cancer is the best current treatment for localized lung cancer, a very aggressive approach should be considered, including a variety of invasive techniques, before accepting 'indeterminate' radiographical findings that imply unresectability. Even if staging rules out curative resection, it may allow entry into induction protocols, with later resection being possible. A systematic approach to staging allows coordination among pulmonologists, radiologists, oncologists and surgeons, and is the basis of a 'rational' approach to the management of lung cancer.

ACKNOWLEDGEMENTS: The authors thank the following physicians for their review and suggestions: Dennis Bowie, Pierre LeBlanc, Mark Turner, Dale Lien, Meyer Balter (Standards Committee, Canadian Thoracic Society, Gloucester, Ontario); Sharon Peters, Peter Paré, Malcolm King, Donald Cockcroft, Irvin Mayers, John Acres, John Morse, Louis-Philippe Boulet, Richard Long, Roger Goldstein, Ian Mitchell, Nigel Duguid, Roland Skraskins, Pierre Larivée, Gordon Ford, Tony Bai, Ainsley Gray (Board, Canadian Thoracic Society, Gloucester, Ontario); Gail Darling (Division of Thoracic Surgery, Mount Sinai Hospital, Toronto, Ontario); Eric Poulin (Division of Thoracic Surgery, Wellesley Central Hospital, Toronto, Ontario); Dean Chamberlain (Department of Pathology, Toronto Hospital, Toronto, Ontario); Gregory D Trachiotis (Division of Cardiothoracic Surgery, Emory University, Atlanta, GA, USA); Todd Sandstrom (Department of Surgery, Watertown General Hospital, Watertown, WI, USA); Mario Gasparri, Kurt A Kralovich, Sohit Khanna, Ilan Rubinfeld (Department of Surgery, Henry Ford Hospital, Detroit, MI, USA); Cairen McNamee (Division of Thoracic Surgery, University of Alberta, Edmonton, Alberta); Fraser Rubens (Division of Cardiac Surgery, Ottawa Heart Institute, Ottawa, Ontario); Vincent Simonetti (Division of Cardiothoracic Surgery, Wayne State University, Detroit, MI, USA); Eric Vallieres (Division of Thoracic Surgery, University of Washington, Seattle, WA, USA).

\section{REFERENCES}

1. Miller JD, Gorenstein LA, Patterson GA. Staging: The key to rational management of lung cancer. Ann Thorac Surg 1992;53:170-8.

2. Sugarbaker DJ, Straus GM. Advances in surgical staging and therapy of non-small-cell lung cancer. Semin Oncol 1993;20:163-72. (Review)

3. Pearson FG. Current status of surgical resection for lung cancer. Chest 1994;106(Suppl 6):337S-9S.

4. Putnam JB Jr. Surgery for stage N2 lung cancer. Semin Thorac Cardiovasc Surg 1993;5:249-57.

5. Luke WP, Pearson FG, Todd TR, et al. Prospective evaluation of mediastinoscopy for assessment of carcinoma of the lung. J Thorac Cardiovasc Surg 1986;91:53-6.

6. Karmy-Jones R, Vallieres E, Lewis Jr JW, Dundas G. Investigation of patients with apparently inoperable lung cancer. Can Respir J 1996;3:309-13.

7. Denoix PF. Enquete permanent dans les centres anticancereux. Bull Inst Nat Hyg (Paris) 1946;i:70.

8. Mountain CF, Carr DT, Anderson WAT. A system for the clinical staging of lung cancer. Am J Roentgenol Radium Ther Nucl Med 1974;120:130-8.

9. Mountain CF. A new international staging system for lung cancer. Chest 1986;89(Suppl 4):225S-33S. (Review)

10. Edelman MJ, Gandara DR, Roach M IIIrd, Benfield JR. Multimodality therapy in stage III non-small cell lung cancer. Ann Thorac Surg 1996;61:1564-72. (Review)
11. Van Raemdonck DE, Schneider A, Ginsberg RJ. Surgical treatment for higher stage non-small cell lung cancer. Ann Thorac Surg 1992;54:999-1013. (Review)

12. Naruke T, Goya T, Tsuchiya R, Suemasu K. Prognosis and survival in resected lung carcinoma based on the new international staging system. J Thorac Cardiovasc Surg 1988;96:440-7.

13. Mooie WJ. Common lung cancers. In: Hasleton PS, ed. Spencer's Pathology of the Lung, 5th edn. New York: McGraw-Hill, 1996:1009-62.

14. Maddaus M, Ginsberg RJ. Cancer/diagnosis and staging. In: Pearson FG, Deslauriers J, Ginsberg RJ, et al, eds. Thoracic Surgery. New York: Churchill Livingstone, 1995:671-90.

15. Shields TW. Diagnosis and staging. In: Baue AE, Geha AS, Hammond GL, et al, eds. Glenn's Thoracic and Cardiovascular Surgery, 5th edn. Norwalk: Appelton and Lange, 1991:325-54.

16. Glazer HS, Kaiser LR, Anderson DJ, et al. Indeterminate mediastinal invasion in bronchogenic carcinoma: CT evaluation. Radiology 1989;173:37-42.

17. Pennes DR, Glazer GM, Wimbish KJ, et al. Chest wall invasion by lung cancer: limitations of CT evaluation. AJR Am J Roentgenol 1985;144:507-11.

18. Stiglbauer R, Schurawitzki H, Klepetko W, et al. Contrast-enhanced MRI for the staging of bronchogenic carcinoma: Comparison with CT and histopathologic staging-preliminary results. Clin Radiol 1991;44:293-8.

19. Cerfolio RJ, Deschamps C, Allen MS, et al. Mainstem bronchial sleeve resection with pulmonary preservation. Ann Thorac Surg 1996;61:1458-63.

20. Luketich JD, Van Raemdonk DE, Ginsberg RJ. Extended resection for higher-stage non-small-cell lung cancer. World J Surg 1993;17:719-28.

21. Faber LP. Sleeve resections for lung cancer. Semin Thorac Cardiovasc Surg 1993;5:238-48.

22. Mack MJ, Aronoff RJ, Acuff TE, et al. Present role of thoracoscopy in the diagnosis and treatment of diseases of the chest. Ann Thorac Surg 1992;54:403-9.

23. Decker DA, Dines DE, Payne WS, et al. The significance of cytologically negative pleural effusion in bronchogenic carcinoma. Chest 1978;74:640-2.

24. Martini N, Flehinger BJ, Zaman MB, et al. Results of resection in non-oat cell carcinoma of the lung with mediastinal lymph node metastases. Ann Surg 1983;198:386-97.

25. Dales RE, Stark RM, Raman S. Computed tomography to stage lung cancer: Approaching a controversy using meta-analysis. Am Rev Respir Dis 1990;141:1096-101.

26. Lewis JW Jr, Pearlberg JL, Beute GH, et al. Can computer tomography of the chest stage lung cancer? Yes and no. Ann Thorac Surg 1990;49:591-6.

27. Daly BDT Jr, Faling LJ, Bite G, et al. Mediastinal lymph node evaluation by computer tomography in lung cancer. J Thorac Cardiovasc Surg 1987;94:664-72.

28. Vallieres E, Waters PF. Incidence of mediastinal node involvement in clinical T1 bronchogenic carcinomas. Can J Surg 1987;30:341-2.

29. Knight SB, Delbeke D, Stewart JR, et al. Evaluation of pulmonary lesions with FDG-PET: Comparison of findings in patients with and without a history of prior malignancy. Chest 1996;109:982-8.

30. Sazon DA, Santiago SM, Soo Hoo GW, et al. Fluorodeoxy-glucose-positron emission tomography in the detection and staging of lung cancer. Am J Respir Crit Care Med 1996;153:417-21.

31. Chin R Jr, Ward R, Keyes JW, et al. Mediastinal staging of non-small cell lung cancer with positron emission tomography. Am J Respir Crit Care Med 1995;152:2090-6.

32. Patz EF Jr, Lowe VJ, Goodman PC, et al. Thoracic nodal staging with PET imaging with 18FDG in patients with bronchogenic carcinoma. Chest 1995; 108:1617-21.

33. Vallieres E, Page A, Verdant A. Ambulatory mediastinoscopy and anterior mediastinotomy. Ann Thorac Surg 1991;52:1122-6.

34. Eagan RT. Management of regionally advanced (stage III) non-small cell lung cancer: LCSG 831. Chest 1994;106(Suppl 6):340S-3S.

35. Rusch VW, Albain KS, Crowley JJ, et al. Neoadjuvant therapy: a novel and effective treatment for stage IIIb non-small cell lung cancer. Ann Thorac Surg 1994;58:290-5.

36. Investigation for mediastinal disease in patients with apparently operable lung cancer. Canadian Lung Oncology Group. Ann Thorac Surg 1995;60:1382-9.

37. van Klaveren RJ, Festen J, Otten HJ, et al. Prognosis of unsuspected 
but completely resectable N2 non-small cell lung cancer. Ann Thorac Surg 1993;56:300-4

38. Patterson GA, Piazza D, Pearson FG, et al. Significance of metastatic disease in subaortic lymph nodes. Ann Thorac Surg 1987;43:155-9.

39. Ginsberg RJ. The role of preoperative surgical staging in left upper lobe tumors. Ann Thorac Surg 1994;57:526-7.

40. Ginsberg RJ, Rice TW, Goldberg M, et al. Extended cervical mediastinoscopy: A single staging procedure for bronchogenic carcinoma of the left upper lobe. J Thorac Cardiovasc Surg 1987:94:673-8.

41. Wang KP, Terri PB. Transbronchial needle aspiration in the diagnosis and staging of bronchogenic carcinoma. Am Rev Respir Dis 1983;127:344-7.

42. Harrow EM, Wang KP. The staging of lung cancer by bronchoscopic transbronchial needle aspiration. Chest Surg Clin N Am 1996;6:223-35.

43. Akamatsu H, Terashima M, Koike T, et al. Staging of primary lung cancer by computed tomography-guided percutaneous needle cytology of mediastinal lymph nodes. Ann Thorac Surg 1996;62:352-5.

44. Silvestri GA, Hoffman BJ, Bhutani MS, et al. Endoscopic ultrasound with fine-needle aspiration in the diagnosis and staging of lung cancer. Ann Thorac Surg 1996;61:1441-6.

45. Lee JD, Ginsberg RJ. Lung cancer staging: The value of ipsilateral scalene lymph node biopsy performed at mediastinoscopy. Ann Thorac Surg 1996;62:338-41.

46. Shields TW. Presentation, diagnosis, and staging of bronchial carcinoma and of the asymptomatic solitary pulmonary nodule. In: Shields TW, ed. General Thoracic Surgery, 4th edn. Malvern: Williams and Wilkins, 1994:1122-54.

47. Hatter J, Kohman LJ, Mosca RS, et al. Preoperative evaluation of stage I and stage II non-small cell lung cancer. Ann Thorac Surg 1994;58:1738-41.

48. Cole FH Jr, Thomas JE, Wilcox AB, Halford HH IIIrd. Cerebral imaging in the asymptomatic preoperative bronchogenic carcinoma patient: is it worthwhile? Ann Thorac Surg 1994;57:838-40.

49. Salbeck R, Grau HC, Artman H. Cerebral tumor staging in patients with bronchial carcinoma by computer tomography. Cancer 1990;66:2007-11.

50. Pearson FG. Current status of surgical resection for lung cancer. Chest 1994;106(Suppl 6):337S-9S

51. Luketich JD, Burt ME. Does resection of adrenal metastases from non-small cell lung cancer improve survival? Ann Thorac Surg 1996;62:1614-6.

52. Miller DL, Onsrulak TA, Pairolero PC, et al. Combined operation for lung cancer and cardiac disease. Ann Thorac Surg 1994;58:989-94.

53. Ginsberg RJ. Preoperative assessment of the thoracic surgical patient: A surgeon's viewpoint. In: Pearson FG, Deslaurier J, Ginsberg RJ, et al, eds. Thoracic Surgery. New York: Churchill Livingston, 1995:29-36

54. Marshall MC, Olson GN. The physiologic evaluation of the lung resection candidate. Clin Chest Med 1993;14:305-20.
55. Cerfolio RJ, Allen MS, Trastek VF, et al. Lung resection in patients with compromised pulmonary function. Ann Thorac Surg 1996;62:348-51.

56. Morice RC, Peters EJ, Ryan MB, et al. Exercise testing in the evaluation of patients at high risk for complications from lung resection. Chest 1992;101:356-61.

57. Lewis JW Jr, Bastanfar M, Gabriel F, Mascha E. Right heart function and prediction of respiratory morbidity in patients undergoing pneumonectomy with moderately severe cardiopulmonary dysfunction. J Thorac Cardiovasc Surg 1994;108:169-75.

58. Maggi G, Casadio C, Pischedda F, et al. Bronchoplastic and angioplastic techniques in the treatment of bronchogenic carcinoma. Ann Thorac Surg 1993;55:1501-7.

59. Ginsberg RJ, Rubinstein LV. Randomized trial of lobectomy versus limited resection for T1 N0 non-small cell lung cancer. Ann Thorac Surg 1995;60:615-23.

60. Massard G, Lyons G, Wihlm JM, et al. Early and long-term results after completion pneumonectomy. Ann Thorac Surg 1995;59:196-200.

61. Feld R, Payne D, Shepherd FA. Small cell lung cancer. In: Shields TW, ed. General Thoracic Surgery, 4th edn. Malvern: Williams and Wilkins, 1994:1241-76.

62. Shepherd FA, Ginsberg RJ, Patterson GA, et al. A prospective study of adjuvant surgical resection after chemotherapy for limited small cell lung cancer: A University of Toronto Lung Oncology Group Study. J Thorac Cardiovasc Surg 1989;97:177-86.

63. Salzer GM, Muller LC, Huber H, et al. Operation for N2 small-cell lung carcinoma. Ann Thorac Surg 1990;49:759-62.

64. Rosenblatt MB, Lisa JR, Collier F. Primary and metastatic broncho-alveolar carcinoma. Dis Chest 1967;52:147-52.

65. Barsky SH, Cameron R, Osann KE, et al. Rising incidence of bronchioloalveolar lung carcinoma and its unique clinicopathologic features. Cancer 1994;73:1163-70.

66. Miller RR, Nelems B, Evans KG, et al. Glandular neoplasia of the lung. A proposed analogy to colonic tumors. Cancer 1988;61:1009-14

67. Paladugu RR, Benfield JR, Pak HY, et al. Bronchopulmonary Kulchitsky cell carcinomas. A new classification scheme for typical and atypical carcinoids. Cancer 1985;55:1303-11.

68. Arrigoni MG, Woolner LB, Bernatz PE. Atypical carcinoid tumors of the lung. J Thorac Cardiovasc Surg 1972;64:413-21.

69. Marty-Ane CH, Costes V, Pujol JL, et al. Carcinoid tumors of the lung: Do atypical features require aggressive management? Ann Thorac Surg 1995;59:78-83.

70. Karmy-Jones R, Vallieres E. Carcinoid crisis after biopsy of a bronchial carcinoid. Ann Thorac Surg 1993;56:1403-5.

71. Colby TV, Koss MN, Travis WD. Atlas of Tumor Pathology - Tumors of the Lower Respiratory Tract. Third Series, Fascicle 13. Washington: Armed Forces Institute of Pathology, 1995.

72. McDonald ML, Deschamps C, Ilstrup DM, et al. Pulmonary resection for metastatic breast cancer. Ann Thorac Surg 1994;58:1599-602. 


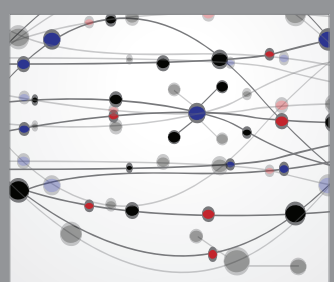

The Scientific World Journal
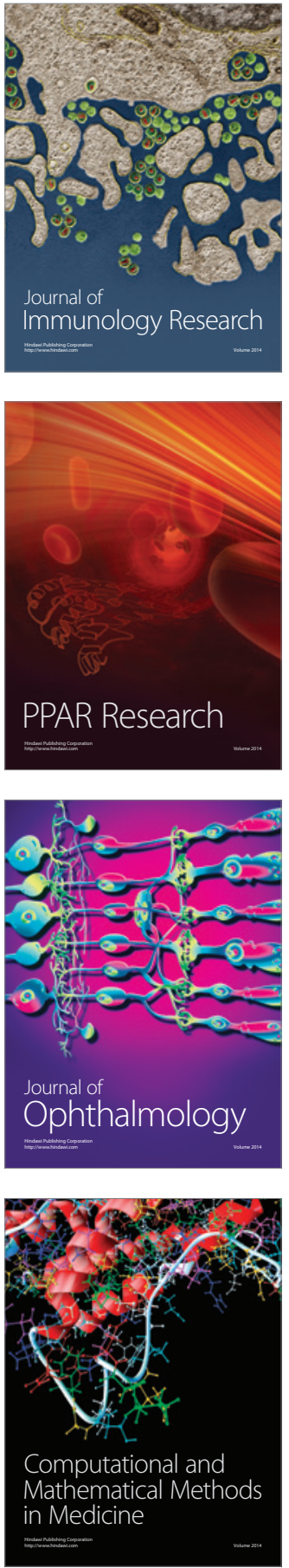

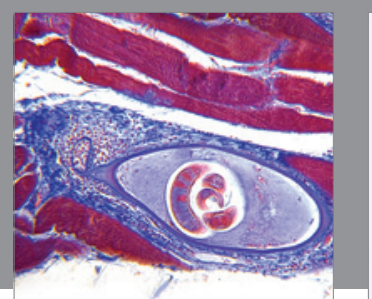

Gastroenterology Research and Practice

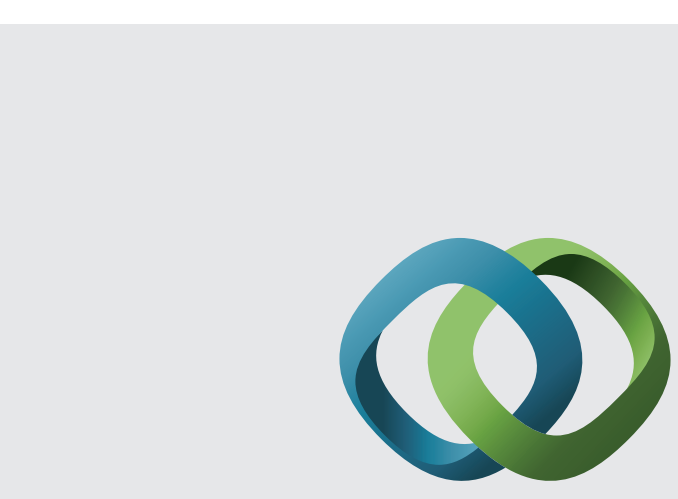

\section{Hindawi}

Submit your manuscripts at

http://www.hindawi.com
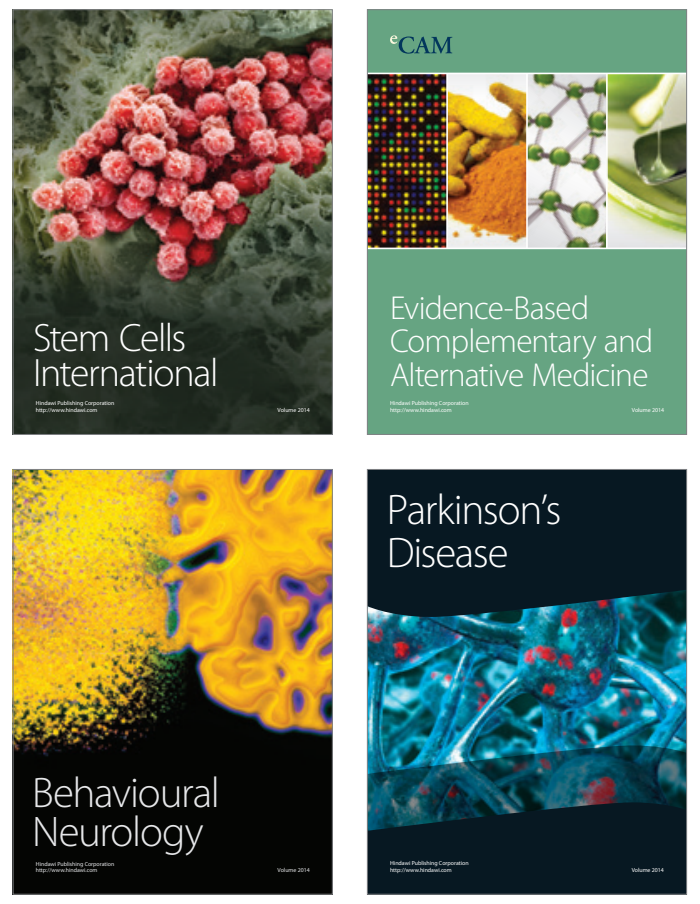
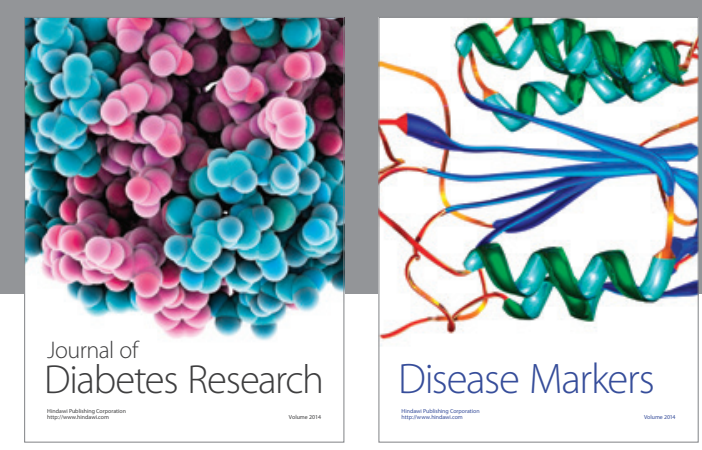

Disease Markers
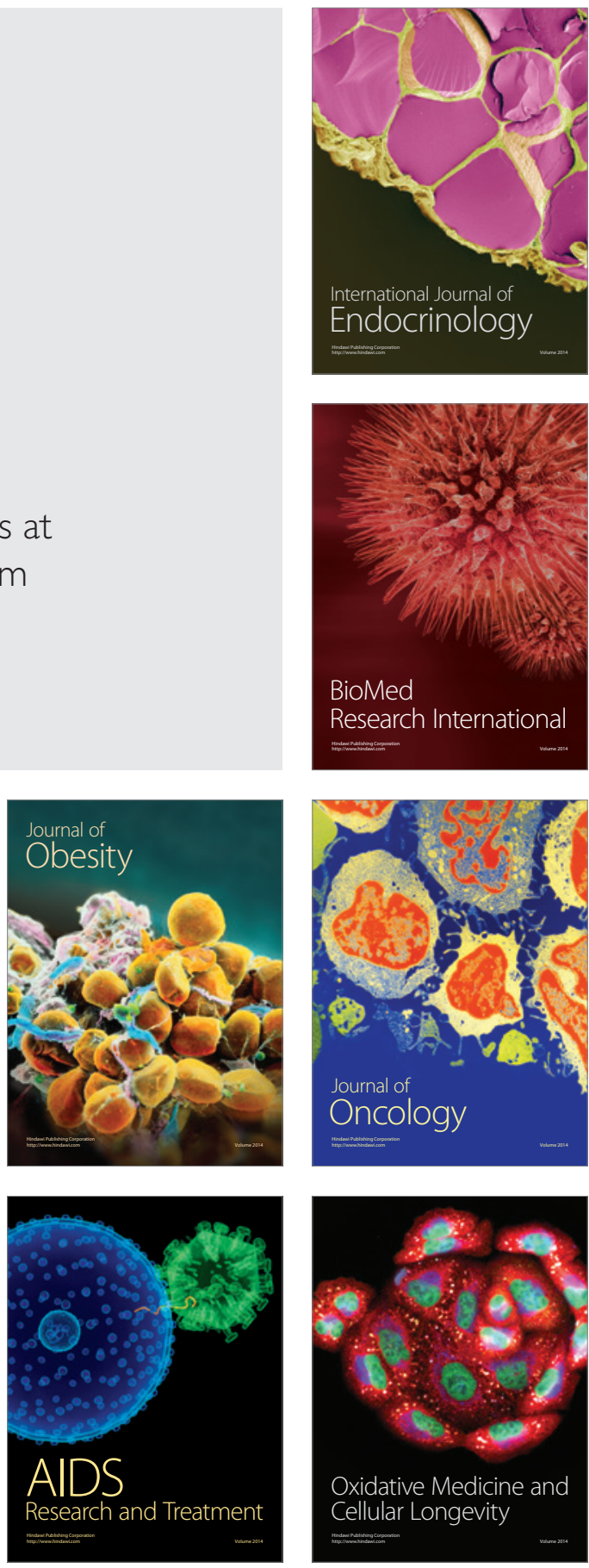